Neurosurg Focus 17 (3):E1, 2004 Click here to return to Table of Contents

\title{
Historical review of cervical arthroplasty
}

\author{
Hoang Le, M.D., Issada Thongtrangan, M.D., and Daniel H. Kim, M.D. \\ Department of Neurosurgery, Stanford University Medical Center, Stanford, California
}

\begin{abstract}
Early attempts at spinal arthroplasty in the 1950s yielded limited success. A revival of this procedure occurred in the 1980s and became a realistic treatment option in the 1990s. Both lumbar and cervical arthroplasties have been introduced in the US since 2000 for randomized, prospective studies in accordance with the Food and Drug Administration (FDA) investigational device exemption provisions. In June 2004 the first lumbar arthroplasty device was approved by the FDA for use in the US. It is likely that cervical arthroplasty will soon follow and may be available for widespread use as early as 2006. In this paper the authors review the historical development of cervical arthroplasty.
\end{abstract}

\section{KEY WORDS • spinal arthroplasty - cervical arthroplasty - disc replacement • degenerative disc disease $\bullet$ historical review}

There is great enthusiasm in the US with regard to the impending approval by the FDA of a cervical arthroplasty device. The concept of arthrodesis was applied to many severe joint disorders until there was widespread acceptance of hip and knee arthroplasty techniques. Nevertheless, whereas arthrodesis of the hip and knee produces severe loss of function, the loss of motion in an intervertebral segment is well tolerated. Why, then, is cervical arthroplasty so appealing, given the excellent clinical outcomes of current arthrodesis techniques?

\section{OVERVIEW}

Concerns for the possibility of acceleration of adjacent-segment disease after fusion have been growing. Furthermore, there are other drawbacks to fusion, including the alteration of spinal biomechanics, graft and hardware complications, and harvest site pain. In addition, it must be realized that neural decompression, not fusion, remains the primary indication and goal of anterior cervical surgery. Cervical arthroplasty provides the opportunity to preserve motion after neural decompression while providing stability. In the following sections, we will discuss key factors that led to the development of cervical arthroplasty.

\section{Adjacent-Segment Disease}

For treatment of cervical disc disease, the ACDF procedure has been well accepted since the 1950s. ${ }^{15,68} \mathrm{Al}$ -

\footnotetext{
Abbreviations used in this paper: $\mathrm{ACDF}=$ anterior cervical discectomy and fusion; DDD = degenerative disc disease FDA = Food and Drug Administration; PCM = porous coated motion; PLL = posterior longitudinal ligament; UHMWPE = ultra-high molecular weight polyethylene.
}

though these surgical procedures are very effective in alleviating symptoms and improving neurological outcomes, the adverse long-term effects of interbody fusion have been the subject of considerable debate. ${ }^{13,79}$ Long-term follow-up studies conducted after anterior cervical fusion have shown that up to $92 \%$ of patients demonstrate adjacent-level degeneration on radiographs. ${ }^{3,17,26,31,37,43}$ Clinical symptoms, however, have not correlated well with the severity of degenerative changes seen on X-ray films. ${ }^{13,17}$, 19,28,43 Biomechanical studies have been performed to evaluate intradiscal pressure and dynamic stability at disc segments adjacent to the fusion. In a human cadaveric model, investigators in several studies have demonstrated increased intradiscal pressure recordings in adjacent disc segments after fusion. ${ }^{20,61,74}$ Clinical studies in which dynamic radiography was used have also shown increased motion at adjacent segments above and below the level of cervical fusion, and this may be a factor associated with deterioration after anterior cervical fusion. 3,23,67

Matsunaga, et al., ${ }^{48}$ developed a mathematical model to evaluate the shear strain of the adjacent disc segments after cervical fusion. For two- or three-level ACDFs, shear strain was increased by $20 \%$ after 1 year and $64 \%$ of adjacent discs that showed an abnormally high strain before the ACDF procedure herniated after the fusion in their follow-up study. A validated finite element analysis has also demonstrated increased internal stress at adjacent segments. ${ }^{41,47}$ Fuller and colleagues ${ }^{24}$ however, were unable to demonstrate adjacent-segment hypermobility after fusion in a human cadaveric model by using stereophotogrammetry. Nevertheless, the older age of the harvested cadaveric specimens as well as the inherent nature of rigor mortis may have counteracted any potential for adjacent segment hypermobility.

Clinically, long-term deterioration after ACDF has been 
documented in several studies. Hilibrand, et al., ${ }^{36}$ studied 374 patients who had undergone anterior cervical fusion and reported that adjacent-segment degeneration with new radiculopathic symptoms occurred in $2.9 \%$ of them per year, with a cumulative rate of $25 \%$ in a 10 -year period. Two thirds of these patients required additional cervical fusion surgeries. Ironically, the incidence of adjacent-segment degeneration was lower in patients with multilevel anterior cervical fusions.

After a follow-up period of almost 10 years, Katsuura, et al., ${ }^{40}$ reported radiographically confirmed changes consisting of adjacent-segment degeneration after anterior cervical fusion in $50 \%$ of patients, with $19 \%$ requiring additional cervical surgeries. Gore and Sepic, ${ }^{30}$ with a mean follow-up duration of 21 years after the initial ACDF, reported that $16 \%$ of their patients required additional cervical surgeries for symptomatic adjacent segment degeneration. In other long-term studies a repeated operation rate of 6 to $7 \%$ has been reported for adjacent-segment disease after ACDF. ${ }^{7,26,46}$ This is in contrast with the repeated operation rate of $1 \%$ for posterior discectomy procedures in which segmental motion is preserved..$^{59,66}$

The natural progression of disc degeneration seems undeniable; in $34 \%$ of asymptomatic patients with normal findings on baseline cervical x-ray films, radiographically confirmed DDD had developed when they were reevaluated 10 years later. ${ }^{28}$ In the same study, $97 \%$ of patients with preexisting disc degeneration showed progression 10 years later. This raises an interesting question in regard to adjacent-segment disease: does the development of this disorder after ACDF represent the natural progression of DDD or does it represent an accelerated degenerative process influenced by the biomechanical effect of fusion? The influence of the latter is supported by documentation of adjacent-segment disease in the pediatric population. Long-term follow-up review of pediatric patients who required anterior cervical fusion for fractures and dislocation revealed a high rate of adjacent-segment disease..$^{52}$ Furthermore, in cases of Klippel-Feil syndrome, in which congenital cervical fusion is known to occur, magnetic resonance imaging studies revealed signal intensities consistent with DDD in adjacent segments in all patients. ${ }^{32}$

The available literature indicates that adjacent-segment disease is affected by both natural history and the biomechanical stress of fusion. It is clear that as many as one of every five patients undergoing a cervical fusion will require another such procedure during a long-term followup period. Despite the immediate gratification of good results following the ACDF procedure for the treatment of cervical disc disease, long-term clinical deterioration leaves room for improvement. The concern that spinal fusion surgery may be a contributing factor to accelerated DDD has spurred an interest in motion preservation surgery. The surgical evolution from arthrodesis to arthroplasty is not new. The overwhelming success of hip arthroplasty over arthrodesis provides a leading example for spinal arthroplasty. We will discuss this in the following section.

\section{Historical Progression From Arthrodesis to Arthroplasty for Hip Surgery}

Traditionally, the generation of pain was attributable to the motion of a degenerative joint, and thus the treatment of pain can be effectively addressed with joint arthrodesis. Before the 1960s, hip fusion was considered the gold standard of treatment for severe osteoarthritis and hip dysplasia. This was very effective for treating pain but left patients with severe disabilities. Several authors have reported satisfactory long-term function after hip arthrodesis, with most patients gainfully employed and able to walk more than 1 mile. Unfortunately, $32 \%$ experienced difficulties with sexual activity, and more than $70 \%$ graded their activity as below average for their age group, particularly the female patients. ${ }^{4,69}$ Another study also showed positional disabilities, including difficulty kneeling or sitting, difficulty putting on and taking off socks, and difficulty climbing stairs. ${ }^{63,69}$ These patients also experienced significant gait changes, with significant limb-length discrepancy. ${ }^{1,29,39}$ Biomechanical data reported by several authors ${ }^{11,34,70}$ also revealed increased loading in the ipsilateral knee and lower lumbar region, which can accelerate degenerative changes in those regions.

Dissatisfaction with the consequences of hip arthrodesis led to the development of total hip arthroplasty. During this procedure, both femoral and acetabular bearing surfaces are surgically replaced with metallic, polymeric, and/or ceramic components. Throughout the 20th century, many different combinations of these materials were explored as bearing surfaces for total hip arthroplasty.

Metal-on-metal total hip replacement devices were first implanted by Wiles ${ }^{78}$ in the 1930s and further developed in the 1950 s and 1960 s by pioneering surgeons like Mc$\mathrm{Kee}^{53}$ and Ring. In 1958, Charnley introduced a "low-friction arthroplasty" based on the principle of a metallic femoral component articulating against a polymeric acetabular component. In 1970, Boutin, et al., ${ }^{8}$ developed the first ceramic-on-ceramic total hip replacement device. Charnley's hard-on-soft bearing concept eventually dominated the other hard-on-hard bearing alternatives based on long-term outcomes. This hard-on-soft bearing concept has influenced the design of other total joint arthroplasty devices as well as total disc arthroplasty.

Today the most widely accepted bearing couple consists of a femoral head fabricated from a cobalt chromium molybdenum alloy articulating against a polymeric component fabricated from UHMWPE. The use of the cobalt chromium molybdenum UHMWPE-bearing couple has provided consistent results in total hip arthroplasties performed worldwide for the past four decades. Nevertheless, polyethylene wear and periprosthetic osteolysis are major obstacles limiting the longevity of these reconstructions. It is now well established that particulate debris generated from the articulating surfaces initiates a cascade of adverse tissue responses leading to osteolysis and in certain cases loosening of the components. ${ }^{6,12,38,42,64,65}$

Recently, researchers have attempted to improve devices currently in use and to design alternative bearing surfaces to reduce wear and possibly osteolysis. Most recently, in the late 1990s, numerous researchers at centers around the world confirmed that cross-linking of UHMWPE, whether by radiation, peroxide, or silane chemistry, can substantially improve the wear performance of the material in hip joint simulators. ${ }^{54-58}$ With hip arthroplasty as a successful treatment superseding hip arthrodesis, the 
progression from spinal arthrodesis to arthroplasty appears to be the next logical step.

\section{Historical Aspects of Cervical Disc Arthroplasty}

Since the 1950s, and especially within the last 10 years, there have been many patented implants designed for restoration of the viscoelastic function as well as preservation of motion in the intervertebral space..$^{71}$ The majority of these implant designs, however, focused on disc replacement in the lumbar spine, whereas a few focused on the cervical spine. Despite the many implant designs, very few have reached the stage of animal studies and fewer have progressed to human clinical trials. ${ }^{71}$

Several factors have influenced the slow progress with spinal arthroplasty. In contrast to knee and hip joints, in which ligamentous structures are of paramount importance in the maintenance of joint stability, the disc itself contributes a significant portion to spinal stability. Disc arthroplasty must take into consideration the additional factor of restoring balance to the facet joints and resetting the instantaneous axis of rotation to the posterior aspect of the disc space. The development of biomaterials for total disc replacement must take into consideration the high demands of a lifetime of strain imparted to the implant. The optimal life span of a spinal implant is 30 to 50 years. During this time the device will undergo between 10 and 30 million cycles; the spine undergoes approximately 100 million flexion cycles during a lifetime. ${ }^{35,75}$ Furthermore, prosthetic wear and the resulting debris, with its associated inflammatory reaction as seen in hip and knee arthroplasty may be a potential source of long-term failure for spinal arthroplasty. To date, however, a significant inflammatory reaction has not been noted for spinal arthroplasty devices. $^{2}$

Early attempts at cervical arthroplasty were met with failure. The first implantation of a cervical arthroplasty device in a human was described by Fernström in 1966.22 $\mathrm{He}$ used an intracorporal endoprosthesis shaped like a metal ball bearing, which he inserted into the disc space of both lumbar and cervical areas. A total of 191 prostheses were implanted in 125 patients. The cervical prostheses were 6 to $10 \mathrm{~mm}$ in diameter and replaced 13 cervical discs in eight patients. Reitz and Joubert, ${ }^{62}$ from South Africa, also reported the use of 75 Fernström cervical prostheses in 32 patients for the treatment of intractable headaches and cervicobrachialgia. Despite these pioneering attempts, Fernström himself admitted poor results. In the vast majority of patients followed for up to 7 years postoperatively, the spherical endoprosthesis created segmental hypermobility with a predisposition to subsidence and migration into the superior endplate. The placement of these devices has subsequently been abandoned in favor of cervical arthrodesis.

In the 1980s there was a resurgence of interest in spinal arthroplasty, specifically lumbar arthroplasty. The SB Charité prosthesis was designed in 1982 and first implanted in 1984. Problems with migration and fatigue fractures led to abandonment of the first two generations of this device. ${ }^{10}$ The Link SB Charité III, now in its third generation, became commercially available in 1987 and is currently the most widely implanted total disc replacement system, with more than 5000 implantations worldwide. ${ }^{33}$
In studies conducted with several years of follow up, good outcomes have been reported in more than $70 \%$ of patients. ${ }^{14,44,80} \mathrm{~A}$ recent report on 60 prospectively randomized patients (41 with SB Charité and 19 with BAK cages) treated in a US center with a follow-up duration of between 1 and 3 years has shown a significant reduction in Oswestry Disability Index scores. ${ }^{51}$ Good results in more than $70 \%$ of patients with a clinical follow-up duration of 10 years after implantation of the SB Charité device have been published, along with reports of complications. .5,73

The Acroflex lumbar disc was also introduced in the 1980s. In one study it was implanted into six patients, yielding fair to poor outcomes. ${ }^{21}$ Concerns about the carcinogenic potential of the rubber as well as failure of the rubber component on subsequent testing have caused the withdrawal of this device from use. ${ }^{71}$

In 1989, another popular disc replacement device emerged: the ProDisc. It is a metal-on-metal design and has yielded favorable long-term outcomes. Marnay published good and excellent outcomes in more than $70 \%$ of patients after follow-up periods of between 7 and 11 years, and in 1999 the ProDisc II featuring design improvements was introduced. ${ }^{72}$ Other authors have also reported favorable outcomes with use of the ProDisc after short-term follow up. ${ }^{5,49}$

So far, of all the spinal arthroplasty devices in use, only the SB Charité and the ProDisc have more than 5 years of clinical follow up. Both have been used in Europe for more than a decade despite the lack of long-term prospective randomized clinical trials. In the US, prospective multicenter, randomized clinical trials were initiated in 2000 for the SB Charité and in 2001 for the ProDisc. The SB Charite was approved for use in the US by the FDA in June 2004.

With the reported success of lumbar arthroplasty devices, renewed enthusiasm has emerged for the prospects of a cervical arthroplasty device. In 1989, the Department of Medical Engineering at Frenchay Hospital, Bristol, United Kingdom, began the initial design process for an artificial cervical joint. Several prototypes were created before clinical trials were initiated in 1991. The initial design was a two-piece, stainless steel, metal-on-metal, ballin-socket configuration with anchoring screws placed anteriorly (Fig. 1). The results of the first human trial in which this cervical prosthesis (called the Cummins-Bris-

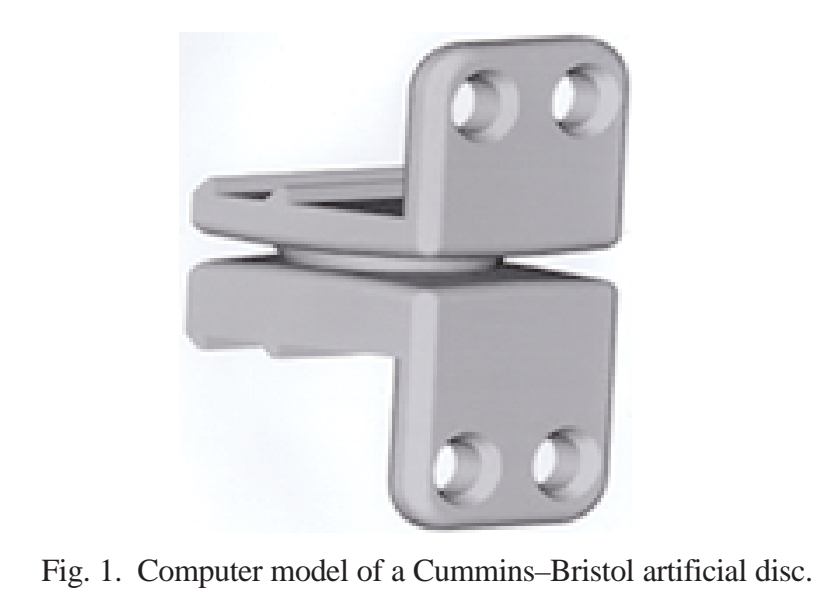


tol artificial cervical joint) was used were reported in 1998. ${ }^{16}$ Between 1991 and 1996, 22 Cummins joints were placed in 20 patients, with follow-up durations ranging from 3 to 65 months (mean 2.4 years).

Results for 18 patients were available for review in 1996, and 16 of these individuals demonstrated continued joint motion of $5^{\circ}$ in flexion and extension. Overdistraction of the disc space and separation of the facet joint accounted for the lack of motion in the remaining cases. Fusion of the interspace did not occur in any patient and adjacent segment degeneration was not observed.

Complications occurred, however, in a significant number of cases. In the first five patients, a single anterior anchoring screw was placed: three patients had partial screw pullout, one had a broken screw, and one joint was subluxed. Subsequently, the technique was modified to include two anchoring screws per device component. Despite this, two cases of partial screw pullout (one broken screw and one joint subluxation) were encountered. Surgical removal of hardware in the latter case revealed the problem to be a manufacturing error; in addition, wear debris was not encountered. Screw complications were attributed to poor screw placement and the use of a uniformsized joint. Dysphagia also developed in all patients (it was persistent in four) and was attributed to the high profile of the anterior limbs of the joint.

Based on the initial experience with the Cummins artificial cervical joint, a second-generation design was im- plemented to allow more physiological cervical motion that would be restrained by that of the facet joints and the surrounding tissues. The new Frenchay cervical disc replaced the lower component of the Cummins joint, which initially was a hemispherical cup, with a shallow ellipsoid saucer (Fig. 2). Freedom of translation and rotation was increased. Also, the upper vertebral component was allowed passively to determine its own axis of rotation so that physiological motion coupled with the facet joint and adjacent vertebral segments could be optimized. In addition, the screw locking mechanism was redesigned and the device was made less bulky.

The results of a 2-year pilot study of the new Frenchay artificial cervical joint were published in 2002. ${ }^{77}$ Fifteen patients who were particularly prone to adjacent-segment degeneration were enrolled in the study. At 2 years postimplantation, cervical motion across the implanted site was preserved in all patients except one. No settling or dislocation of the device was noted. Despite screw breakage in two of 60 instances, no screw backout was noted. Four patients experienced neck pain on full extension and one of them eventually required removal of the device. The joint in question was noted to be loose, with the surrounding fibrous tissue devoid of inflammation or wear debris. The authors attributed the device failure to excessive bone removal at the time of surgery and transference of load sharing to the facet joint.

In a prospective nonrandomized fashion, Wigfield and

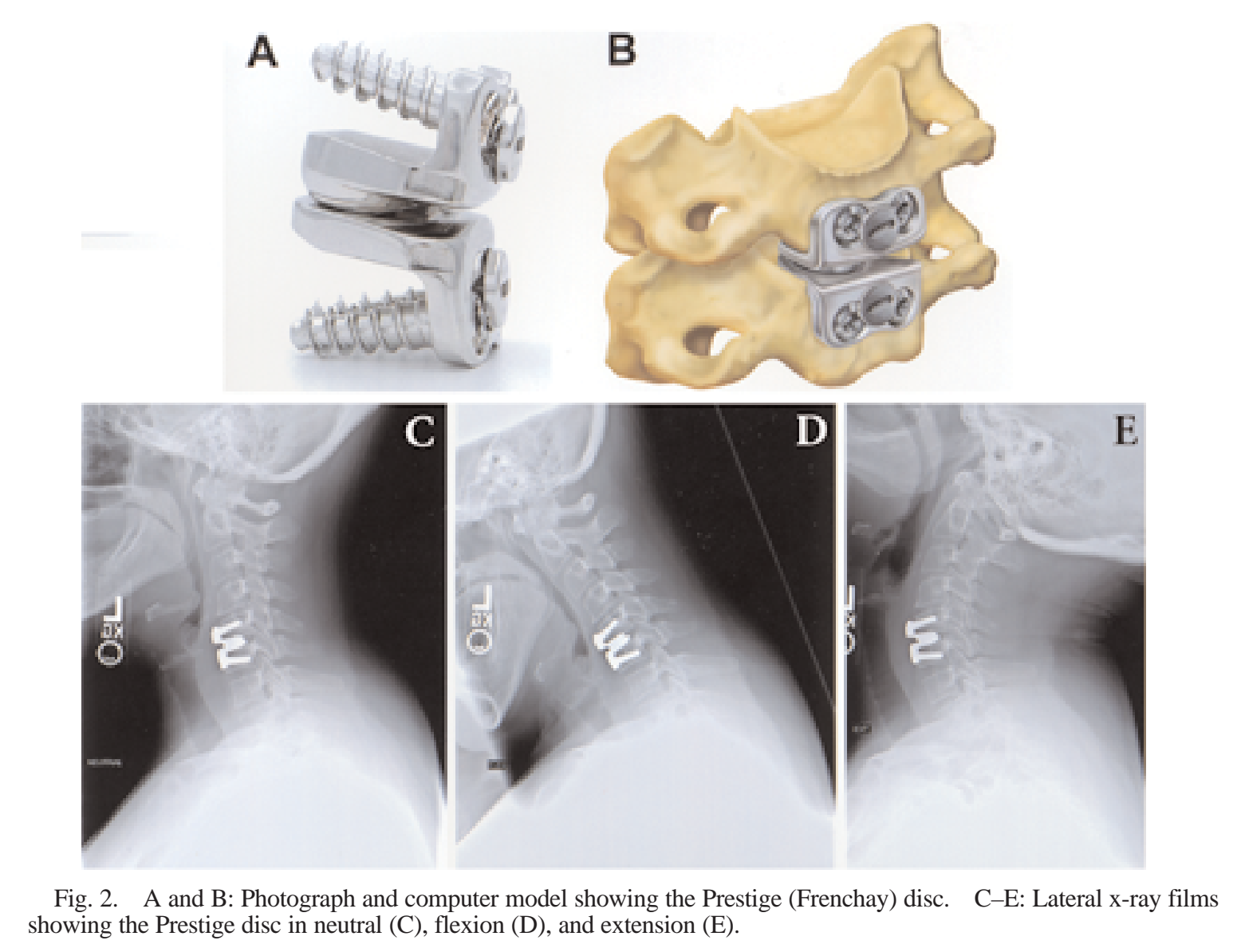


coworkers $^{76}$ also compared adjacent-segment motion after implantation of the Frenchay disc with a one-level arthrodesis. In the group undergoing fusion a significant increase in adjacent-level movement (mean $9^{\circ}$ ) was demonstrated based on angular measurements at the 12-month follow-up visit compared with the group of patients in whom the Frenchay joint was placed. The fusion group experienced increases of their adjacent segment motion by $5 \%$ at 6 months and $15 \%$ at 1 year. Subgroup analysis revealed that the increase in movement occurred predominantly at the disc space that was preoperatively regarded as normal. Overall adjacent-level movement for the group that received the Frenchay device was minimally affected. Similar findings of motion preservation and minimal effects on adjacent-segment motion were also noted earlier in biomechanical studies conducted by other authors. ${ }^{18}$

In theory, the decrease in adjacent-segment motion seen with the use of an artificial joint compared with that associated with fusion should reduce the incidence of adjacent-segment disease. This remains to be firmly demonstrated in future long-term studies.

In August 2000 the first prospective, randomized trial comparing cervical arthroplasty with iliac crest autograft fusion by using the Frenchay disc (now called Prestige) was initiated at multiple centers in Australia, Europe, and the United Kingdom. Preliminary results presented at the 18th Annual Meeting of the North American Spine Society in October 2003 reportedly demonstrated favorable outcomes in the arthroplasty group, with preservation of motion and lack of progression in adjacent-segment disease. A randomized, prospective US investigational device exemption study involving the Prestige disc was initiated in 2002 and is ongoing. This product may gain FDA approval for US markets by 2006.

With the reported success of the modified Bristol discs, several other artificial cervical discs have reached the clinical testing stage. In 2001, Pointillart, ${ }^{60}$ an orthopedic surgeon, reported the use of a titanium cervical arthroplasty device fashioned according to the design of the unipolar hip replacements used for treating hip fractures. The device consisted of a carbon sliding surface at the cephalad aspect of the prosthesis and a titanium base secured by two screws to the caudal vertebral body (Fig. 3), and it was implanted in 10 patients between 1998 and 1999. Un-

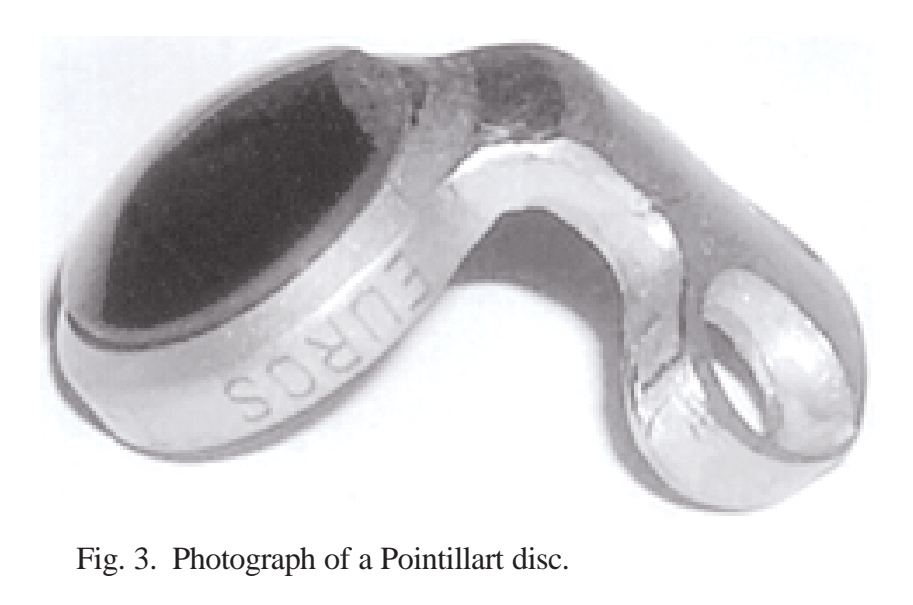

fortunately, mobility was not maintained in eight patients (five experienced circumferential fusion, in two the vertebra fused posterior to the device, and one had bridging fusion anteriorly). In the two patients who suffered persistent mobility, persistent neck pain was also noted. Further use of this device has not been documented.

In contrast to the metal-on-metal design of the Bristol disc, a metal-on-plastic design called the Bryan disc emerged in the late 1990s (Fig. 4). Named after its American inventor, Vincent Bryan, the disc consists of a polyurethane core that articulates between two titanium alloy shells that include convex porous surfaces for bone ingrowth. The device is rotationally unconstrained, allows for $11^{\circ}$ of motion in flexion, extension, and lateral bending, $2 \mathrm{~mm}$ of translation, is coupled to the surrounding soft tissues, and allows for shock absorption. In vivo testing in chimpanzees and goats demonstrated motion preservation, device safety, ingrowth of bone into the prosthesis shell, and no inflammatory response in the surrounding tissues. ${ }^{9}$

Clinical trials in which the Bryan disc was used were initiated in January 2000 for the treatment of a single cervical disc level. In January 2001 a second arm of the study was initiated in which the Bryan disc was evaluated for the treatment of two adjacent cervical levels. Preliminary outcomes of the European prospective multicenter trial in which the Bryan disc was used for single-level cervical disc disease were published by Goffin and coworkers ${ }^{25}$ in 2002. The clinical success rate was $86 \%$ in 60 patients at 6 months and $90 \%$ in 30 patients at 1 year, both of which exceeded the targeted rate of $85 \%$. Motion was preserved in all patients, with no evidence of device migration. In 2003, a follow-up report presented intermediate results from the multicenter single-level Bryan disc trial and also preliminary data from the bilevel arthroplasty trial. ${ }^{27}$ In the single-level group, 100 patients reached the 1-year time point and 51 reached the 2-year mark. Success rates at 6 months, 1 year, and 2 years were 90,86 , and $90 \%$, respectively. The bilevel group included 43 patients with 1-year data and 29 with 2 -year data. The success rate for this group was $82 \%$ at 6 months and $96 \%$ at 1 year. Motion was maintained in both surgical groups, averaging more than $7^{\circ}$ per level for the range of flexion and extension at the 1-year evaluation. No device failure or subsidence was noted in any patient.

Australian prospective trials of the Bryan disc have been ongoing since 2001. A randomized, prospective US investigational device exemption trial of the Bryan disc was also initiated in May 2002. Currently, in excess of 2000 Bryan discs have been implanted in patients in more than 17 countries outside the US since its approval for use in those countries in 2002. As yet, no significant complications associated with this device have been reported. Paravertebral ossifications noted in approximately $30 \%$ of patients have responded to early treatment with a 2 -week course of nonsteroidal antiinflammatory drugs and have not affected overall clinical outcomes (Fig. 5). ${ }^{9}$

Along the same lines as the metal-on-plastic concept, the PCM artificial disc was developed recently with two different designs to address the integrity of the PLL after cervical decompression (Fig. 6). Rather than using a polyurethane core as in the Bryan disc, the PCM disc consists 

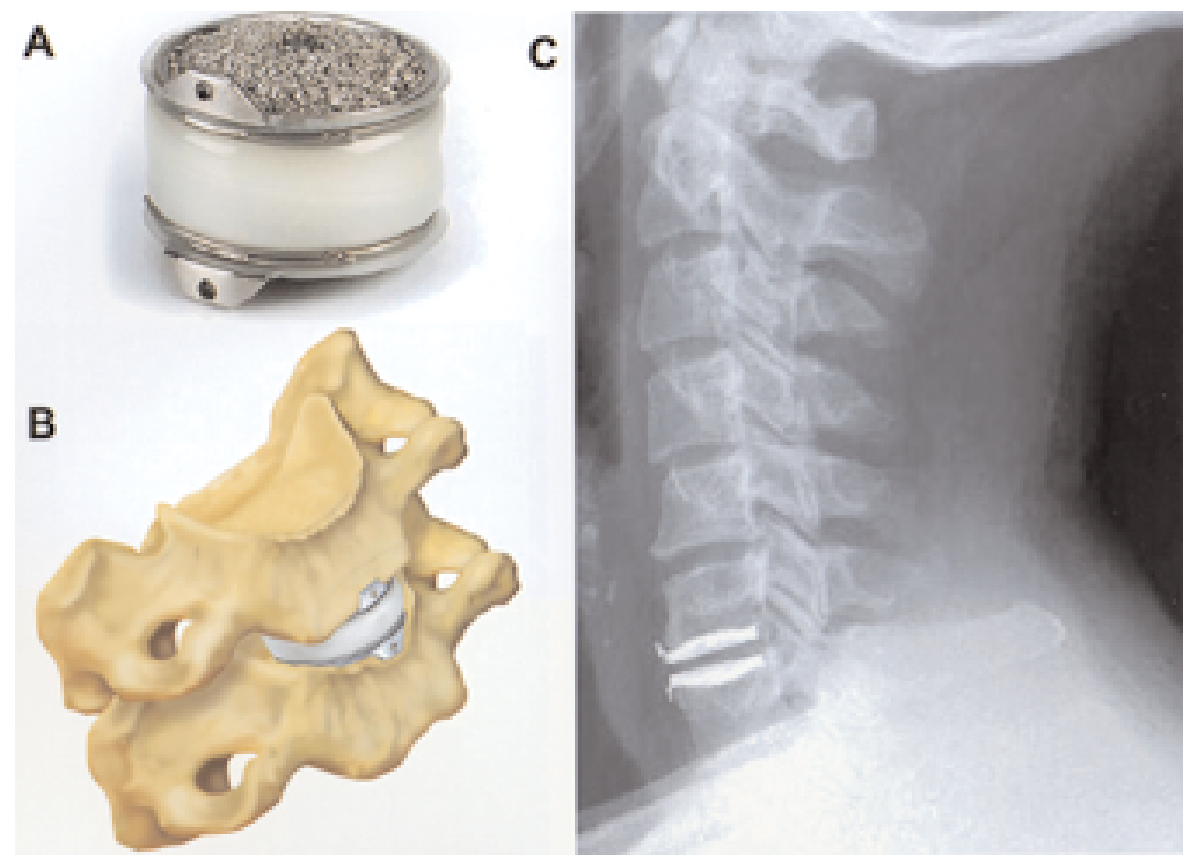

Fig. 4. A and B: Photograph and computer model showing a Bryan disc. C: Lateral x-ray films showing a singlelevel Bryan disc in neutral position.

of the traditional UHMWPE compound found in hip and knee arthroplasties. It is structured for load bearing rather than being a ball-in-socket design. The porous coated component was modeled after the ingrowth capabilities of the titanium- and carbon-coated SB Charite discs. The low-profile PCM disc design is favored in situations in which the PLL is preserved, whereas the fixed PCM disc design with anchoring screws is preferred in situations in which the PLL is removed. Biomechanical studies have

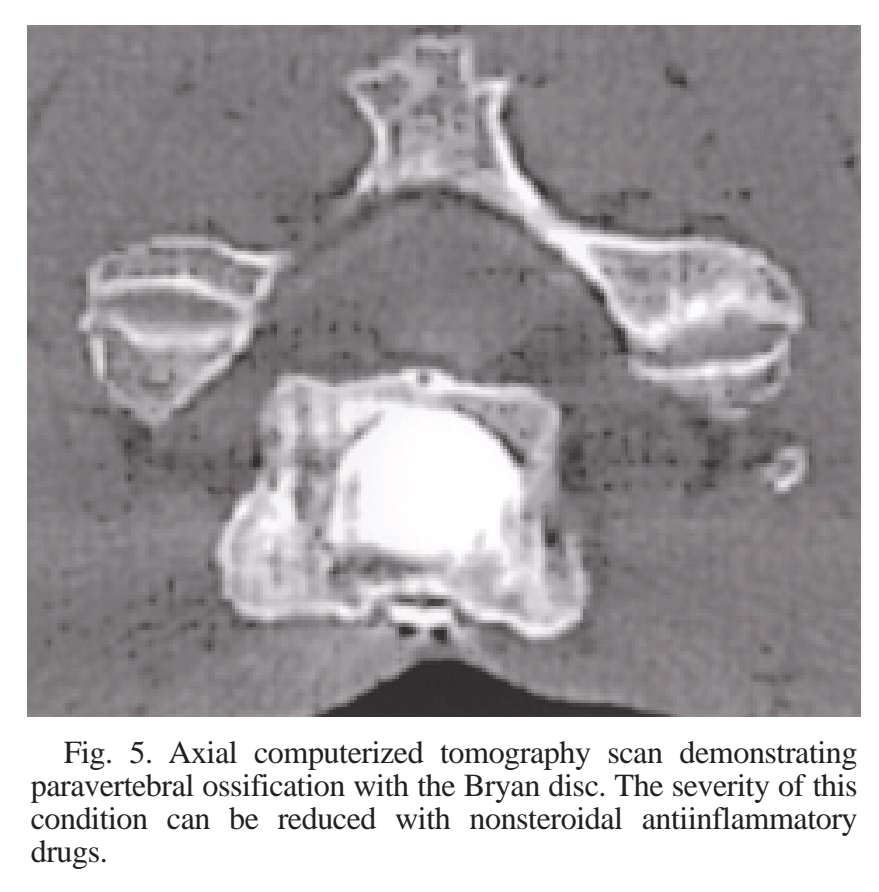

revealed the destabilizing effect of resecting the PLL with anterior discectomy in a cadaveric model ${ }^{50}$ Initial animal testing with the PCM disc in goats followed for 6 months revealed stability of the construct with no evidence of particulate debris and porous bone ingrowth. At the 19th annual meeting of the Cervical Spine Research Society in June 2003, preliminary clinical outcomes in 20 patients in whom the PCM disc was used were reported. Odom criteria revealed good and excellent outcomes in 95\% of patients. Clinical trials with the PCM disc are expected to begin soon in the US. This device may be available to the US market by 2008 .

With the success of the lumbar ProDisc device, a simi-

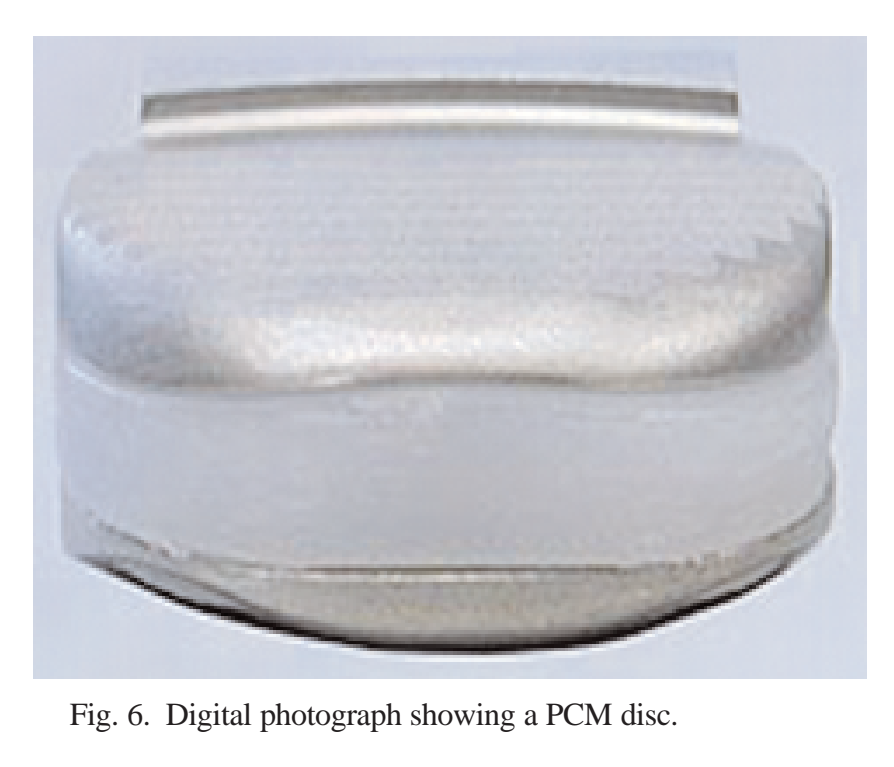

Neurosurg. Focus / Volume 17 / September, 2004 


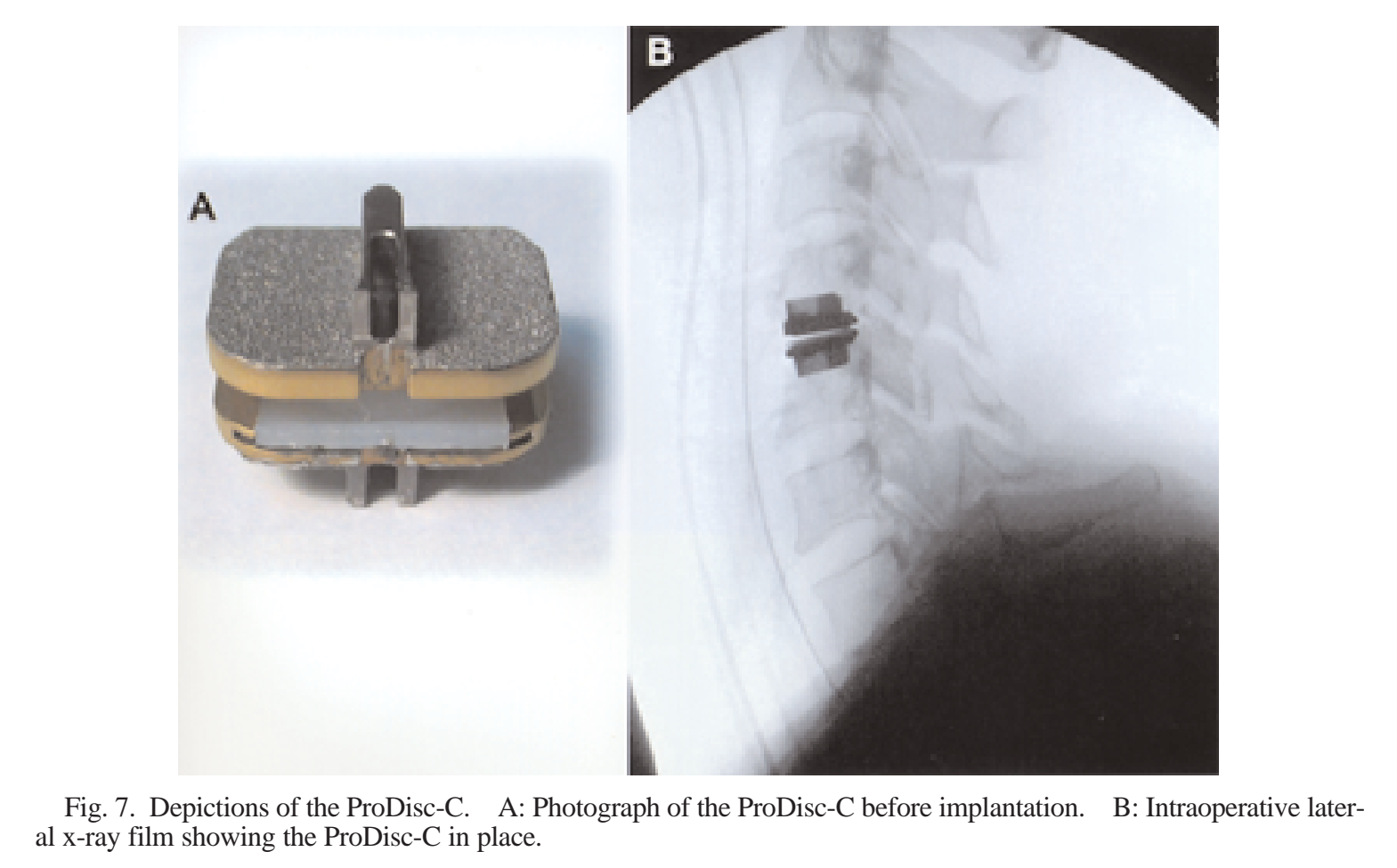

lar construct for cervical arthroplasty was designed. The ProDisc-C, as it is called, is also a metal polyethylene ball-in-socket design with two metal fins (Fig. 7). A multicenter randomized prospective clinical trial in the US with this device is currently ongoing. Other cervical arthroplasty devices in the midst of preclinical trials are actively being developed and tested and will likely emerge in the coming years (Fig. 8). With the recent FDA ap-

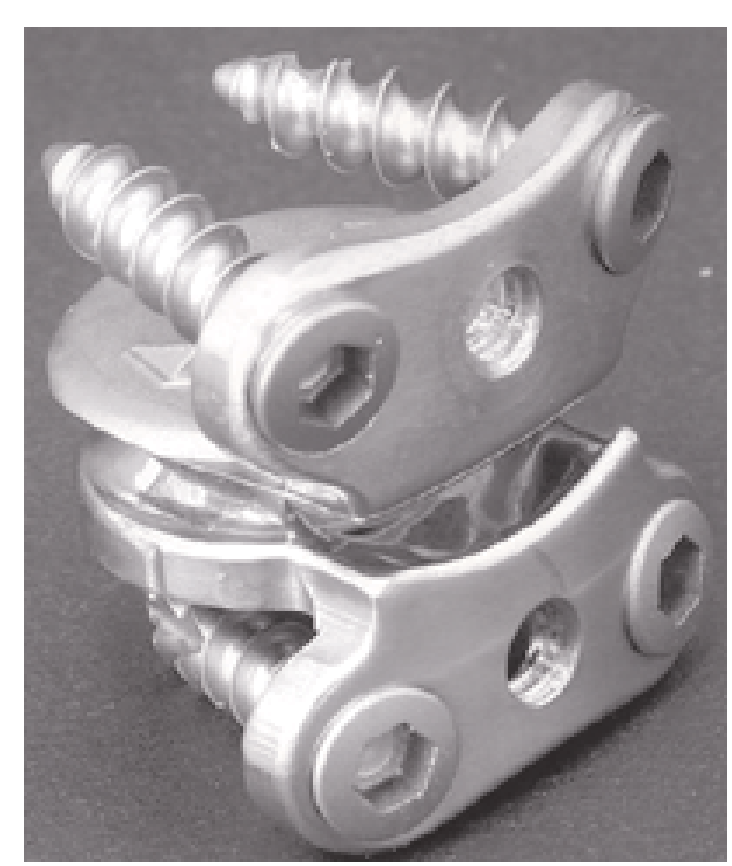

Fig. 8. Photograph showing the CerviCore (FlexCore) disc. proval of the first lumbar arthroplasty device in the US, it is likely that cervical arthroplasty will soon follow and can be available to US markets as early as 2006 .

\section{CONCLUSIONS}

The historic progression of cervical arthroplasty is based on the clinical success encountered with hip, knee, and subsequently lumbar arthroplasties. Despite the positive short-term outcomes with cervical arthrodesis, up to $25 \%$ of patients who undergo ACDF will require another surgery within 10 years, primarily for adjacent-segment disease. Can cervical arthroplasty prevent or reduce the incidence of adjacent-segment disease? We will soon find out. Regardless, preserving and restoring natural motion to the cervical spine is intuitively desirable in the treatment of cervical disc disease. If primary clinical outcomes from the use of cervical arthroplasty can match or surpass those of cervical arthrodesis, a new treatment standard for cervical disc disease will have emerged.

\section{References}

1. Ahlback SO, Lindahl O: Hip arthrodesis. The connection between function and position. Acta Orthop Scand 37:77-87, 1966

2. Anderson PA, Rouleau JP, Bryan VE, et al: Wear analysis of the Bryan Cervical Disc prosthesis. Spine 28:S186-S194, 2003

3. Baba H, Furusawa N, Imura S, et al: Late radiographic findings after anterior cervical fusion for spondylotic myeloradiculopathy. Spine 18:2167-2173, 1993

4. Barnhardt T, Stiehl JB: Hip fusion in young adults. Orthopedics 19:303-306, 1996

5. Bertagnoli R, Kumar S: Indications for full prosthetic disc arthroplasty: a correlation of clinical outcome against a variety of indications. Eur Spine J 11 (Suppl 2):S131-S136, 2002

6. Bohler M, Kanz F, Schwarz B, et al: Adverse tissue reactions to 
wear particles from Co-alloy articulations, increased by alumina-blasting particle contamination from cementless Ti-based total hip implants. A report of seven revisions with early failure. J Bone Joint Surg Br 84:128-136, 2002

7. Bohlman HH, Emery SE, Goodfellow DB, et al: Robinson anterior cervical discectomy and arthrodesis for cervical radiculopathy. Long-term follow-up of one hundred and twenty-two patients. J Bone Joint Surg Am 75:1298-1307, 1993

8. Boutin P, Christel P, Dorlot JM, et al: The use of dense alumina-alumina ceramic combination in total hip replacement. J Biomed Mater Res 22:1203-1232, 1988

9. Bryan VE Jr: Cervical motion segment replacement. Eur Spine J 11 (Suppl 2):S92-S97, 2002

10. Buttner-Janz K, Schellnack K, Zippel H: Biomechanics of the SB Charite lumbar intervertebral disc endoprosthesis. Int Orthop 13:173-176, 1989

11. Callaghan JJ, Brand RA, Pedersen DR: Hip arthrodesis. A longterm follow-up. J Bone Joint Surg Am 67:1328-1335, 1985

12. Callaghan JJ, Pedersen DR, Johnston RC, et al: Clinical biomechanics of wear in total hip arthroplasty. Iowa Orthop J 23: $1-12,2003$

13. Cherubino P, Benazzo F, Borromeo U, et al: Degenerative arthritis of the adjacent spinal joints following anterior cervical spinal fusion: clinicoradiologic and statistical correlations. Ital J Orthop Traumatol 16:533-543, 1990

14. Cinotti G, David T, Postacchini F: Results of disc prosthesis after a minimum follow-up period of 2 years. Spine 21: 995-1000, 1996

15. Cloward RB: The anterior approach for removal of ruptured cervical disks. J Neurosurg 15:602-617, 1958

16. Cummins BH, Robertson JT, Gill SS: Surgical experience with an implanted artificial cervical joint. J Neurosurg 88:943-948, 1998

17. DePalma AF, Rothman RH, Lewinnek GE, et al: Anterior interbody fusion for severe cervical disc degeneration. Surg Gynecol Obstet 134:755-758, 1972

18. DiAngelo DJ, Roberston JT, Metcalf NH, et al: Biomechanical testing of an artificial cervical joint and an anterior cervical plate. J Spinal Disord Tech 16:314-323, 2003

19. Dohler JR, Kahn MR, Hughes SP: Instability of the cervical spine after anterior interbody fusion. A study on its incidence and clinical significance in 21 patients. Arch Orthop Trauma Surg 104:247-250, 1985

20. Eck JC, Humphreys SC, Lim TH, et al: Biomechanical study on the effect of cervical spine fusion on adjacent-level intradiscal pressure and segmental motion. Spine 27:2431-2434, 2002

21. Enker P, Steffee A, McMillin C, et al: Artificial disc replacement. Preliminary report with a 3-year minimum follow-up. Spine 18:1061-1070, 1993

22. Fernstrom U: Arthroplasty with intercorporal endoprothesis in herniated disc and in painful disc. Acta Chir Scand Suppl 357: 154-159, 1966

23. Fielding JW: Normal and selected abnormal motion of the cervical spine from the second vertebra to the seventh cervical vertebra based on cineroentgenography. J Bone Joint Surg Am 46:1779-1781, 1964

24. Fuller DA, Kirkpatrick JS, Emery SE, et al: A kinematic study of the cervical spine before and after segmental arthrodesis. Spine 23:1649-1656, 1998

25. Goffin J, Casey A, Kehr P, et al: Preliminary clinical experience with the Bryan Cervical Disc Prosthesis. Neurosurgery 51: 840-847, 2002

26. Goffin J, Geusens E, Vantomme N, et al: Long-term follow-up after interbody fusion of the cervical spine. J Spinal Disord Tech 17:79-85, 2004

27. Goffin J, Van Calenbergh F, van Loon J, et al: Intermediate follow-up after treatment of degenerative disc disease with the Bryan Cervical Disc Prosthesis: single-level and bi-level. Spine 28:2673-2678, 2003
28. Gore DR: Roentgenographic findings in the cervical spine in asymptomatic persons: a ten-year follow-up. Spine 26: 2463-2466, 2001

29. Gore DR, Murray MP, Sepic SB, et al: Walking patterns of men with unilateral surgical hip fusion. J Bone Joint Surg Am 57: 759-765, 1975

30. Gore DR, Sepic SB: Anterior discectomy and fusion for painful cervical disc disease. A report of 50 patients with an average follow-up of 21 years. Spine 23:2047-2051, 1998

31. Goto S, Mochizuki M, Kita T, et al: Anterior surgery in four consecutive technical phases for cervical spondylotic myelopathy. Spine 18:1968-1973, 1993

32. Guille JT, Miller A, Bowen JR, et al: The natural history of Klippel-Feil syndrome: clinical, roentgenographic, and magnetic resonance imaging findings at adulthood. J Pediatr Orthop 15:617-626, 1995

33. Guyer RD, Ohnmeiss DD: Intervertebral disc prostheses. Spine 28 (Suppl 15):S15-S23, 2003

34. Hauge MF: The knee in patients with hip joint ankylosis. Clinical survey and bio-mechanical aspects. Acta Orthop Scand 44:485-495, 1973

35. Hedman TP, Kostuik JP, Fernie GR, et al: Design of an intervertebral disc prosthesis. Spine 16 (Suppl 6):S256-S260, 1991

36. Hilibrand AS, Carlson GD, Palumbo MA, et al: Radiculopathy and myelopathy at segments adjacent to the site of a previous anterior cervical arthrodesis. J Bone Joint Surg Am 81: 519-528, 1999

37. Hunter LY, Braunstein EM, Bailey RW: Radiographic changes following anterior cervical fusion. Spine 5:399-401, 1980

38. Jasty MJ, Floyd WE III, Schiller AL, et al: Localized osteolysis in stable, non-septic total hip replacement. J Bone Joint Surg Am 68:912-919, 1986

39. Karol LA, Halliday SE, Gourineni P: Gait and function after intra-articular arthrodesis of the hip in adolescents. J Bone Joint Surg Am 82:561-569, 2000

40. Katsuura A, Hukuda S, Saruhashi Y, et al: Kyphotic malalignment after anterior cervical fusion is one of the factors promoting the degenerative process in adjacent intervertebral levels. Eur Spine J 10:320-324, 2001

41. Kim YE, Goel VK, Weinstein JN, et al: Effect of disc degeneration at one level on the adjacent level in axial mode. Spine 16: 331-335, 1991

42. Kobayashi S, Takaoka K, Saito N, et al: Factors affecting aseptic failure of fixation after primary Charnley total hip arthroplasty. Multivariate survival analysis. J Bone Joint Surg Am 79:1618-1627, 1997

43. Kulkarni V, Rajshekhar V, Raghuram L: Accelerated spondylotic changes adjacent to the fused segment following central cervical corpectomy: magnetic resonance imaging study evidence. J Neurosurg (Spine 1) 100:2-6, 2004

44. Lemaire JP, Skalli W, Lavaste F, et al: Intervertebral disc prosthesis. Results and prospects for the year 2000. Clin Orthop Relat Res 337:64-76, 1997

45. Link HD: History, design and biomechanics of the LINK SB Charite artificial disc. Eur Spine J 11 (Suppl 2):S98-S105, 2002

46. Lunsford LD, Bissonette DJ, Jannetta PJ, et al: Anterior surgery for cervical disc disease. Part 1: Treatment of lateral cervical disc herniation in 253 cases. J Neurosurg 53:1-11, 1980

47. Maiman DJ, Kumaresan S, Yoganandan N, et al: Biomechanical effect of anterior cervical spine fusion on adjacent segments. Biomed Mater Eng 9:27-38, 1999

48. Matsunaga S, Kabayama S, Yamamoto T, et al: Strain on intervertebral discs after anterior cervical decompression and fusion. Spine 24:670-675, 1999

49. Mayer HM, Wiechert K, Korge A, et al: Minimally invasive total disc replacement: surgical technique and preliminary clinical results. Eur Spine J 11 (Suppl 2):S124-S130, 2002

50. McAfee PC, Cunningham B, Dmitriev A, et al: Cervical disc 
replacement-porous coated motion prosthesis: a comparative biomechanical analysis showing the key role of the posterior longitudinal ligament. Spine 28 (Suppl 20):S176-S185, 2003

51. McAfee PC, Fedder IL, Saiedy S, et al: SB Charite disc replacement: report of 60 prospective randomized cases in a US center. J Spinal Disord Tech 16:424-433, 2003

52. McGrory BJ, Klassen RA: Arthrodesis of the cervical spine for fractures and dislocations in children and adolescents. A longterm follow-up study. J Bone Joint Surg Am 76:1606-1616, 1994

53. McKee GK, Watson-Farrar J: Replacement of arthritic hips by the McKee-Farrar prosthesis. J Bone Joint Surg Br 48: 245-259, 1966

54. McKellop H, Shen FW, Lu B, et al: Development of an extremely wear-resistant ultra high molecular weight polyethylene for total hip replacements. J Orthop Res 17:157-167, 1999

55. McKellop H, Shen FW, Lu B, et al: Effect of sterilization method and other modifications on the wear resistance of acetabular cups made of ultra-high molecular weight polyethylene. A hipsimulator study. J Bone Joint Surg Am 82:1708-1725, 2000

56. McKellop HA, Campbell P, Park SH, et al: The origin of submicron polyethylene wear debris in total hip arthroplasty. Clin Orthop 311:3-20, 1995

57. Muratoglu OK, Merrill EW, Bragdon CR, et al: Effect of radiation, heat, and aging on in vitro wear resistance of polyethylene. Clin Orthop 417:253-262, 2003

58. Muratoglu OK, O'Connor DO, Bragdon CR, et al: Gradient crosslinking of UHMWPE using irradiation in molten state for total joint arthroplasty. Biomaterials 23:717-724, 2002

59. Murphey F, Simmons JC, Brunson B: Surgical treatment of laterally ruptured cervical disc. Review of 648 cases, 1939 to 1972. J Neurosurg 38:679-683, 1973

60. Pointillart V: Cervical disc prosthesis in humans: first failure. Spine 26:E90-E92, 2001

61. Pospiech J, Stolke D, Wilke HJ, et al: Intradiscal pressure recordings in the cervical spine. Neurosurgery 44:379-385, 1999

62. Reitz H, Joubert MJ: Intractable headache and cervico-brachialgia treated by complete replacement of cervical intervertebral discs with a metal prosthesis. S Afr Med J 38:881-884, 1964

63. Roberts CS, Fetto JF: Functional outcome of hip fusion in the young patient. Follow-up study of 10 patients. J Arthroplasty 5:89-96, 1990

64. Santavirta S, Xu JW, Hietanen J, et al: Activation of periprosthetic connective tissue in aseptic loosening of total hip replacements. Clin Orthop 352:16-24, 1998

65. Schmalzried TP, Shepherd EF, Dorey FJ, et al: The John Charnley Award. Wear is a function of use, not time. Clin Orthop 381:36-46, 2000

66. Scoville WB: Types of cervical disk lesions and their surgical approaches. JAMA 196:479-481, 1966
67. Shoda E, Sumi M, Kataoka O, et al: Developmental and dynamic canal stenosis as radiologic factors affecting surgical results of anterior cervical fusion for myelopathy. Spine 24: 1421-1424, 1999

68. Smith GW, Robinson RA: The treatment of certain cervicalspine disorders by anterior removal of the intervertebral disc and interbody fusion. J Bone Joint Surg Am 40:607-624, 1958

69. Sofue M, Kono S, Kawaji W, et al: Long term results of arthrodesis for severe osteoarthritis of the hip in young adults. Int Orthop 13:129-133, 1989

70. Sponseller PD, McBeath AA, Perpich M: Long-term follow-up of hip arthrodesis performed in young patients. Hip:43-53, 1984

71. Szpalski M, Gunzburg R, Mayer M: Spine arthroplasty: a historical review. Eur Spine J 11 (Suppl 2):S65-S84, 2002

72. Tropiano P, Huang RC, Girardi FP, et al: Lumbar disc replacement: preliminary results with ProDisc II after a minimum follow-up period of 1 year. J Spinal Disord Tech 16:362-368, 2003

73. van Ooij A, Oner FC, Verbout AJ: Complications of artificial disc replacement: a report of 27 patients with the SB Charite disc. J Spinal Disord Tech 16:369-383, 2003

74. Weinhoffer SL, Guyer RD, Herbert M, et al: Intradiscal pressure measurements above an instrumented fusion. A cadaveric study. Spine 20:526-531, 1995

75. White AA III, Panjabi MM: The basic kinematics of the human spine. A review of past and current knowledge. Spine 3:12-20, 1978

76. Wigfield C, Gill S, Nelson R, et al: Influence of an artificial cervical joint compared with fusion on adjacent-level motion in the treatment of degenerative cervical disc disease. J Neurosurg (Spine 1) 96:17-21, 2002

77. Wigfield CC, Gill SS, Nelson RJ, et al: The new Frenchay artificial cervical joint: results from a two-year pilot study. Spine 27:2446-2452, 2002

78. Wiles P: The surgery of the osteoarthritic hip. Br J Surg 45: 488-497, 1958

79. Williams JL, Allen MB Jr, Harkess JW: Late results of cervical discectomy and interbody fusion: some factors influencing the results. J Bone Joint Surg Am 50:277-286, 1968

80. Zeegers WS, Bohnen LM, Laaper M, et al: Artificial disc replacement with the modular type SB Charite III: 2-year results in 50 prospectively studied patients. Eur Spine J 8:210-217, 1999

Manuscript received June 15, 2004.

Accepted in final form July 26, 2004.

Address reprint requests to: Daniel H. Kim, M.D., Department of Neurosurgery, Stanford University Medical Center, Room R-201, Edwards Building, 300 Pasteur Drive, Stanford, California 943055327. email: neurokim@stanford.edu. 